\title{
环保节能技术在建筑装饰装修中的应用研究
}

\author{
于乃峰* \\ 北京丽贝亚建设工程有限公司, 北京 100041
}

\begin{abstract}
摘 要: 近几年来我国建筑行业发展速度在不断加快, 建筑工程项目不断增多, 其施工技术也得到了创新和改进, 使得建筑行业的整体 发展水平在不断提高。目前我国建筑行业在发展的过程中, 建筑装饰装修是其中十分重要的一个环节, 而在该环节的施工中, 施工技术对 于施工效果会产生很大影响, 所以在我国提出了可持续发展战略以后, 环保节能技术就在我国建筑装饰装修施工中得到了推广, 环保节能 技术与传统的施工技术相比, 能够有效提高能源资源的利用率, 同时保护环境，与我国可持续发展的战略相适应。所以，本文就对建筑装 饰装修施工中的环保节能技术进行分析，研究应用策略。
\end{abstract}

关键词：环保节能技术；建筑装饰装修；应用

\section{Research on Application of Environmental Protection and Energy Saving Technology in Building Decoration}

\author{
Nai-Feng $\mathrm{Yu}^{*}$ \\ Beijing Libeiya Construction Engineering Co., Ltd. Beijing 100041, China
}

\begin{abstract}
In recent years, the development speed of China's construction industry has been accelerating, construction projects have been increasing, and its construction technology has also been innovated and improved, which has made the overall development level of the construction industry continue to improve. At present, in the development process of China's construction industry, building decoration is a very important part of it. In the construction of this link, construction technology will have a great impact on the construction effect, so after China proposed the sustainable development strategy, environmental protection and energy saving technology has been promoted in China's building decoration construction. Compared with traditional construction technology, environmental protection and energy saving technology can effectively improve the utilization rate of energy resources, while protecting the environment, and is compatible with China's sustainable development strategy. Therefore, this article analyzes the environmental protection and energy saving technology in building decoration construction and studies the application strategies.
\end{abstract}

Keywords: Environmental protection and energy saving technology; building decoration; application

\section{一、前言}

在建筑行业的施工中, 建筑装饰装修施工是其中十分重要的环节, 尤其是随着人们生活水平的不断提高, 人们对于建筑装饰装修的风格 和质量也有了更高的要求, 所以相关技术也在不断创新和发展。进人 21 世纪以后, 我国经济社会在快速发展的同时也带来了严重的生态和 环境问题, 所以我国提出了可持续发展的战略, 该战略对建筑装饰装修工作也带来了很大影响, 因为建筑装饰装修施工需要应用大量的资 源, 还会对环境产生很大影响, 所以在该战略实施以后, 我国建筑装饰装修行业中也出现了很多节能环保技术, 将该技术应用于施工中, 能够促进建筑行业的可持续发展。因此施工方需要在建筑装饰装修施工中，加强对环保节能技术的有效应用。

\section{二、环保节能技术在建筑装饰装修中应用的意义}

(一) 节约资源

首先环保节能技术中的一个重要特点就在于其节能性, 这里的节能主要指的是节约资源, 与常规的施工技术相比, 环保节能技术在应用 时, 能够通过技术的改进来提高资源的利用率, 从而达到减少资源使用量的目的。我国建筑行业的资源消耗量普遍比较高, 建筑装饰装修 施工中也会使用大量的能源和资源，而环保节能技术在其中的应用却能够有效节约资源，降低工程的施工成本。

\section{( 二 ) 保护环境}

环保节能技术的另一个优势在于其环保性, 也就是在应用的过程中不会对环境造成过高的污染或破坏。由于建筑行业的能耗普遍比较 高, 在使用的过程中对环境所造成的影响也比较大, 这与我国的环保要求是相悖的, 但是将环保节能技术应用于建筑装饰装修中, 无论是 选择环保材料还是应用环保的施工技术，都能够有效提高施工的环保性能，减轻其对环境的污染和影响 ${ }^{[1]}$ 。

\section{(三) 提高人们的生活质量}

环保节能技术的应用不仅仅会影响建筑装饰装修工程的施工, 还会影响到人们的生活。环保节能技术在应用之后, 在建筑装饰装修施工 的过程中, 各种环保材料、环保技术和节能技术的应用, 可以提高建筑装饰装修的环保节能效果, 施工方通过对环保材料的使用和装饰装

*通讯作者: 于乃峰, 1987 年 11 月, 男, 汉, 山东日照人, 现任北京丽贝亚建设工程有限公司技术负责人, 初级职称, 大专学历。研究方向: 室内装饰施工技术。 
修的设计, 可以提高对自然资源的利用率, 降低建筑在使用过程中的能源消耗, 同时减少其污染的排放, 使得建筑的环保性能增强, 而这 样也能够为住户营造一个更加环保和健康的生活环境，从而提高住户的生活质量。

\section{三、环保节能技术在建筑装饰装修中应用的现状和问题}

(一) 应用现状

自从我国提出了可持续发展的战略要求之后, 我国建筑行业的发展也在不断改进, 尤其是各种环保节能技术的应用, 使得建筑的节能环 保性建筑提高, 对建筑的结构和功能也产生了很大的影响, 对于我国建筑行业的可持续发展是十分有利的。但是在建筑装饰装修施工中可 以发现，环保节能技术的应用，主要是对其中的施工材料和相关的结构设计进行改进，而在该过程中，需要相关管理部门制定完善的制度 和规范, 对建筑装饰装修行业的施工进行管理和监督, 这样才能够使其与可持续发展的需求相适应 ${ }^{[2]}$ 。另外, 环保节能技术在建筑装饰装修 中的有效应用, 需要不断推动建筑用户装饰装修的标准化进度, 对装饰装修工程的施工设计等各个环节制定统一的标准和流程, 将环保节 能的理念融人其中，这样才能够达到最佳的应用效果，同时也能够保证环保节能技术的广泛应用。

(二) 存在的问题

我国的可持续发展战略在近几年来不断发展和宣传, 当前人们已经认识到了环保和节能工作的重要性, 也认同了可持续发展的相关理 念, 在这种情况下, 人们对于自身的生活品质也有了更高的要求, 追求更加环保节能和绿色健康的生活, 这在一定程度上推动了我国建筑 行业向着可持续发展的方向改进，但与此同时，也给建筑行业的发展提出了更高的要求。我国建筑的装饰装修施工本身就会对人们的生活 产生直接影响, 所以人们对其的要求会更加严格, 但是在建筑行业中可以发现, 装饰装修施工与建筑的其他施工项目相比, 其发展相对比 较缓慢和落后, 所以, 我国并没有制定出比较完善的管理制度和体系, 相关的管理规范和标准也不完善; 除此之外, 我国建筑行业在快速 发展的同时，也使得建筑市场不断扩大，当前建筑市场上各种材料的种类和性能十分繁杂，一些节能环保材料中掺杂了很多假冒伪劣的材 料，这本身就会影响到建筑装饰装修工作的节能环保性，使得我国建筑装饰装修施工工作难以与人们的环保节能需求相适应。

\section{四、建筑装饰装修中的环保节能技术}

建筑的装饰装修施工工作主要分为两个部分：建筑外围的装饰装修和建筑内部的装饰装修，所以建筑装饰装修中的环保节能技术也主要 指的是这两方面的环保节能技术。

(一) 建筑外围装饰技术

在建筑装饰装修施工中，对建筑外围进行装饰装修，主要是对建筑的墙体进行施工，环保节能技术的应用就是对墙体进行节能环保施 工，提高墙体的保温性能，降低施工难度和成本。对建筑外围进行装饰装修时，环保节能施工主要集中于以下几点：

1. 外墙涂料

建筑墙体的性能很大程度上会受到外墙涂料的影响, 因为涂料本身对墙体能够起到防水、美观和保温的效果, 所以如果外墙的涂料性能 比较高，就可以提高建筑外墙的性能。目前我国建筑外墙普遍使用的涂料都存在着一定的缺陷，很容易受到外界风吹、日晒和雨淋等环境 条件的影响, 涂料容易发生脱落, 所以在进行环保节能施工时, 就需要选择一些特殊的涂刷材料, 尤其是要重视涂料的保温效果, 这样可 以有效防止室内外的热量交换，从而使建筑减少冬季取暖和夏季制冷的能源消耗。

2. 幕墙的使用

当前我国很多的建筑都会设计幕墙结构, 而幕墙结构本身在设计和施工时的环保节能效果就会影响到建筑外墙的环保节能性。通常建筑 的幕墙结构主要是对建筑内部起到一定的围护和保温效果, 但是想以后达到更好的应用效果, 施工方需要谨慎选择幕墙的材料, 尽量选择 金属幕墙和石材幕墙，然后在幕墙与建筑墙体之间使用保温材料来增强建筑外墙的保温性能 ${ }^{[3]}$ 。

最后可以在建筑的外部加设一个玻璃幕墙, 玻璃幕墙与其他材质的幕墙相比, 这种幕墙的材质是玻璃, 所以, 具有更好的采光性, 能够 增加室内的采光, 同时其装饰效果也更强, 而如果在这种幕墙中进行保温方面的设计, 那么, 就能够有效提高建筑内部热量, 可以有效降 低能源损耗，如图1所示。

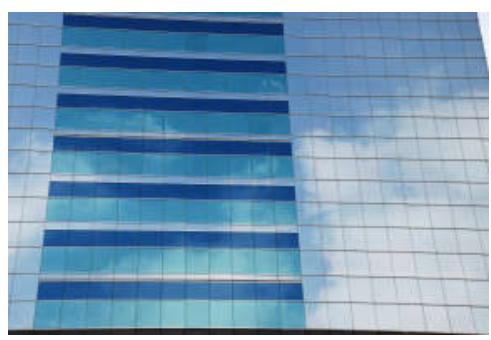

图1 玻璃幕墙

（二）内部装饰技术

建筑装饰装修施工中，内部的装饰装修对于人们生活所产生的影响是最为直接的，因为其会直接影响到建筑的内部环境，进而影响人们 的生活质量。建筑内部的装饰装修施工主要集中在以下几点:

1. 门窗设置

门窗是建筑与外部环境进行热量交换和沟通的主要位置, 所以, 如果门窗的设置不合理, 就会直接影响到建筑的保温性能, 影响建筑 内部热量, 所以, 在进行建筑的内部装饰装修施工时, 环保节能技术需要重视门窗的设置, 要提高门窗的密封性, 尽量选择一些密封性好 
且传导系数小的材料, 在施工结束之后, 还需要在其墙体的连接处进行密挂 ${ }^{[4]}$ 。

2. 内墙设计

建筑的内墙主要指的是建筑室内用于隔断的墙体和承重墙, 这种墙体对于建筑内部的空间规划和美观性会产生很大影响, 所以, 环保节 能技术在应用时, 施工方需要增强墙体的功能性, 要在保证其承重效果的同时, 增强其保温性能和隔音性能, 同时增强其美观性, 以此来 减少建筑的能源损耗。

3. 地面设计

地面对于室内温度会产生很大的影响, 不同材质的地面对于室内温度的影响是不同的, 当前比较常用的地面施工材料, 主要包括水 泥、地砖、木质材料和塑料橡胶材料, 这些材料本身的传热系数和保温性能差异比较大, 进而影响到室内的温度。

4. 棚顶设计

棚顶的设计主要指的是建筑内部天花板的设计, 环保节能技术在其中的应用, 需要在保证棚顶功能性的同时减少能源损耗, 棚顶设计会 影响到室内空气的流通, 所以在进行设计时, 需要增强对自然风的利用 ${ }^{[5]}$ 。如图2所示。

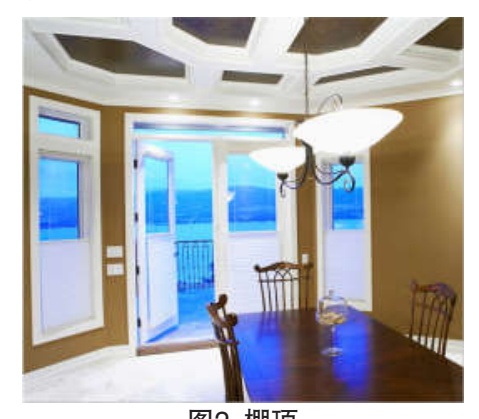

图2 棚顶

\section{五、环保节能技术在建筑装饰装修中的应用}

(一) 使用环保节能材料

在建筑装饰装修施工中想要提高其环保节能性能, 首先施工方需要使用环保节能材料来代替传统的材料, 提高材料本身的环保性和节能 性, 这样就可以提高整个建筑的环保节能性能。目前在对建筑进行装饰装修施工时，环保材料的应用主要集中于室内的装饰装修施工中。 首先施工方需要选择隔热性能更好的材料进行墙壁和门窗的设计, 增强建筑的保温性能, 防止建筑物内外热量的交换, 从而有效防止冬季 室内热量的流失; 其次, 各种家电的使用也会影响到室内的热量, 所以在建筑的环保节能装饰装修施工中, 施工方需要提出家电选择和使 用的相关建议, 比如购买节能电器、节水电器和环保的器材, 这些家电和设备的使用, 可以使建筑在使用的过程中提高其节能节水和环保 的效果, 减少能源损耗; 最后, 在建筑的地板和天花板装饰装修施工中, 施工方需要选择保温性能比较强的材料, 也可以在其中设置隔热 层或使用隔热材料，利用这种方式来保证室内的温度，营造最为舒适的室内环境 ${ }^{[6]}$, 如图3所示。

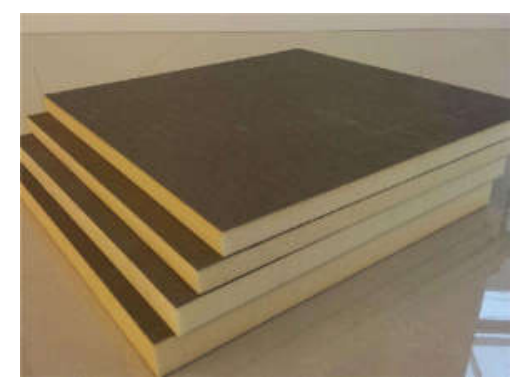

图3 聚氨酯保温材料

除此之外, 建筑在进行装饰装修时, 人们最为关注的就是健康问题, 而这其中比较具有代表性的就是甲醛问题, 室内装饰材料中如果含 有甲醛就会给人们的身体健康带来巨大威胁, 所以在室内装饰装修的环保节能技术中控制甲醛释放也是一项重要技术。为了控制甲醛的释 放, 在选择装饰装修材料时可以减少胶合类材料的使用, 或者在选择家具时直接进行成品定制, 将定制好的家具在户外放置一段时间, 在 装修结束之前放置到室内，这样也可以防止家具中残留的甲醛对室内环境造成污染。

(二) 应用环保节能技术

目前我国的建筑装饰装修施工中出现了很多环保节能技术, 所以, 可以将这些技术实际应用于施工工作中, 以提高施工的节能环保 性。环保节能技术的应用主要集中于材料的选择、机械设备的使用、施工工艺的选择和人员管理等方面, 所以在施工时, 施工方首先要谨 慎选择环保节能的施工材料, 同时需要加强材料使用过程的控制, 减少材料浪费; 机械设备的选择主要根据工程的实际施工需要, 选择功 率最为合适的设备, 同时要对相关的工序进行合理搭配, 提高设备的使用率; 施工工艺的选择则需要考虑到该工程的施工标准和人们的使 用要求, 同时要兼具环保节能性; 最后人员管理方面, 需要加强对人员的培训, 提高相关施工人员和管理人员的环保节能意识 ${ }^{[7]}$ 。

(三) 细节设计 
建筑的装饰装修施工是一项十分系统也十分复杂的工作, 其内容十分繁杂, 想要进行环保节能的施工, 需要考虑到其中的方方面面, 任 何一个环节都不能出现疏漏, 所以在建筑装饰装修的环保节能技术应用中, 施工方需要加强对细节处的设计。这里的细节设计主要指的是 材料的选择、室内的布局和线路的规划, 要使这些都能够满足环保节能的要求, 这样就可以保证建筑装饰装修的环保节能效果 ${ }^{[8]}$ 。

六、结语

综合上文内容可以得知，环保节能技术与传统的装饰装修施工技术相比，在实际应用的过程中，能够有效节约资源，保护环境，同时能 够为人们营造一个更加健康和绿色的生活环境, 对于提高人们生活质量也有着重要作用, 与我国可持续发展的战略要求相适应, 所以, 我 国的建筑装饰装修施工中, 很多施工单位都应用了该技术, 可是在具体使用过程中还存在着各种问题, 使得其效用得不到充分的发挥。建 筑装饰装修中的环保节能技术比较多, 如果能够对其进行正确合理的应用, 就能够提高整个建筑的节能环保性能, 所以, 在施工中, 施工 方需要加强对建筑外围装饰技术和内部装饰技术的研究, 将环保节能技术应用于其中, 同时使用环保节能材料代替传统材料, 从细节中出 发，保证环保节能技术的有效应用。

\section{参考文献:}

[1]张学岗.建筑装饰装修环保节能技术的应用研究[J].居舍, 2019(28):19.

[2]宫志远.节能环保化在建筑装饰装修工程施工中的应用[J].居舍, 2019(25):17.

[3]林华旮.浅析环保节能技术在建筑装饰装修中的应用[J].江西建材, 2019(07):156-157.

[4]杨翼源.节能环保化在建筑装饰装修工程施工中的应用 [J].江西建材, 2019(05):160+162.

[5]刘建成,刘建东,李冰.基于环保节能技术在建筑装饰装修中应用的探析 [J]. 居舍, 2019(14):22.

[6]党高朋.节能环保化在建筑装饰装修工程施工中的应用 [J].居舍, 2019(10):22.

[7]陈剑平.提高环保节能技术在建筑装饰装修中的应用[J].四川水泥, 2018(12):120.

[8]陈龙兴, 吴瑾,钟懿萌,王君.基于环保节能技术在建筑装饰装修中应用的探析[J].农家参谋, 2018(19):230. 